\section{Keep politics out of academia in Israel}

Israel's thriving academic establishment is being ripped apart by the Israeli government's apparent drive to use academics for political ends.

To bolster its agenda of developing settlements in the West Bank occupied territories, the Israeli military's Council for Higher Education in Judea and Samaria has upgraded a small college there, formerly known as Ariel College, to university status. Millions of dollars are to be poured into the university's budget to attract researchers, circumventing Israel's usual channels for academic funding.

In response, more than 1,100 senior faculty members from all over Israel — over one-quarter of the country's total - have signed a petition rejecting the upgrade (see go.nature.com/dqte9c). The planned upgrade is also opposed by the presidents of all seven research universities in Israel and by the influential planning and budgeting committee of the state's Council for Higher Education.

The legitimacy of building settlements on occupied land is disputed in Israel and deplored worldwide. Ever since the occupation of the West Bank 45 years ago, Israeli academia has largely remained outside the political struggle. But Ariel University, which is closed to Palestinians, creates a dilemma for academics there: participate and thereby endorse the settlements, or boycott and be branded as the enemy. Such political meddling can only ruin Israel's academic structure in the long run. Nir Gov Weizmann Institute of Science, Rehovot, Israel. nir.gov@weizmann.ac.il

\section{Turkey must build on science reforms}

As chair of the Committee on Freedom and Responsibility in the Conduct of Science at the International Council for Science
(ICSU), I was alarmed to read of the arrest in Turkey in June of Kemal Gürüz (http://doi. org/h47), twice a victim of the country's apparent crackdown on academic freedom (Nature 487, 19-20; 2012). The committee monitors such cases and calls for greater protection of the human rights of individual scientists.

Gürüz, as a former president of Turkey's Council of Higher Education, has helped to raise education standards significantly in the country. He has also facilitated higher-education opportunities abroad for hundreds of Turkish students - particularly in the United States, where he was a Fulbright scholar and, later, chairman of the Turkish Fulbright Commission. His rearrest seems to relate to his attempted modernization of the education system, including provisions to educate Turkish students to become scientists.

Turkey's scientific contribution will depend on building up its research structure and continuing the reforms initiated by influential academics such as Gürüz.

Bengt Gustafsson ICSU, Paris, France.

bengt.gustafsson@fysast.uu.se

\section{Time to accept conservation triage}

Like the troubled California condors Gymnogyps

californianus (Nature 486, $451 ; 2012$ ), more than $80 \%$ of endangered US species are imperilled by threats that cannot be eliminated, only managed.

These species are "conservation reliant” (J. M. Scott et al. Conserv. Lett. 3, 91-97; 2010).

For example, the endangered Kirtland's warbler (Setophaga kirtlandii) has exceeded its recovery goals as a result of control of the brown-headed cowbird (Molothrus ater), which lays its eggs in warbler nests, and maintenance of warbler habitat through vegetation management. These conservation actions will be required in perpetuity if the species is to avoid extinction. But funding of such management is inadequate for all but the most iconic species, such as the condor.

Society must commit to increased investment in conservation intervention, which will take greater political motivation and broader conservation partnerships than at present. We must begin to prioritize conservation efforts and accept that conservation triage may sometimes be necessary.

John A. Wiens $P R B O$

Conservation Science, Corvallis, Oregon,USA.jwiens@prbo.org

Dale D. Goble, J. Michael Scott University of Idaho, Moscow, Idaho, USA.

\section{Call for clear policy on deceased authors}

William Laurance and his colleagues (Nature http://doi.org/ h5f; 2012) identify four of their paper's authors as deceased and confirm that all had previously verified that they wanted to be co-authors. Without such indication, there is a risk that deceased authors might be included on questionable grounds - for example, as little more than a dedication.

Increasingly, authors' contributions to papers have to be explicitly justified. Although opinions of what constitutes enough to warrant authorship can vary between individuals and journals, most would endorse your journal's policy that "all the listed authors [must] have agreed all of the contents" of the final version of the submitted paper (see go.nature.com/qnanep).

Because this criterion may not be fulfilled for a deceased author who has genuinely contributed to the work, journals should not only denote authors who died before submission but also specify the date of their death and the contribution they made (see, for example, go.nature. com/pymlxb and go.nature.com/ jxqr8n). The author list should not include unwarranted names of the deceased, for whom a dedication can be included in the acknowledgements.

Vincent Nijman Oxford Brookes University, UK.

vnijman@brookes.ac.uk

\section{How to allay fears over nanomaterials}

Regulating the use and engineering of nanomaterials is problematic owing to scientific uncertainty and controversy over their safety. To pave the way for regulatory approval and to build consumer confidence, the European Commission's Joint Research Centre and the European Academies Science Advisory Council have identified factors to help assess the benefits and risks of nanomaterials to health (see go.nature.com/ utmi3d).

Our analysis indicates that formulation of a coherent public policy will depend on scientists closing knowledge gaps in safety research, on gathering more data to connect science and regulation, and on training graduate students in nanotechnology research. Policies will need to be flexible to accommodate fresh discoveries in this rapidly advancing technology.

More dialogue on nanomaterials is needed among private and public research groups, regulators and the public.

Genetic modification of crops has taught us that consumer acceptance as well as regulatory approval are needed for successful implementation of new bioscience technologies. To limit alarmist media assertions about nanomaterials, scientists have a responsibility to provide accessible and accurate information for the public. Robin Fears European Academies Science Advisory Council, Halle, Germany. Peter Gehr University of Bern, Switzerland.gehr@ana.unibe.ch Elke Anklam Institute for Health and Consumer Protection, EC Joint Research Centre, Ispra, Italy. 